The Energy Conservation Newsletter - spring 2014

\section{Dr. Watts' Brilliant Savings}

Spring brings on diverse activities, such as Earth Day and Phillies baseball. While at first glance, these groups seem to have little in common with each other, a closer inspection reveals some interesting similarities. So read on and let's compare a baseball team with Jefferson's Energy team (all 11,000 of us!)

Without even leaving the dugout, one obvious difference is that the Phillies play only half a year, while our Energy Team has a season that never ends. Regardless of past successes, the Jefferson Team is constantly seeking new ways to cut costs.

On the back of this newsletter, you'll read about 3 diverse individuals who opened their eyes, saw waste and called the Energy Team's attention to the situation and brought about positive results. How about you? -

\section{Batt-er Up!}

Remember those frigid mornings we had last winter, featuring single-digit bitter cold weather and all just a few short months ago? Didn't you think about that stretch of bare warm air duct in your basement and/ or attic that needs insulating?

Well, Dude, grab a batt - of insulation - and swing for the bleachers!

\title{
ROOT, ROOT, ROOT FOR THE HOME TEAM
}

\section{CCx Spring Training}

The Heating, Ventilating and Air Conditioning (HVAC) systems in many existing buildings operate inefficiently. As a result, energy and money are wasted.

Retrocommissioning $(\mathrm{RCx})$ is a proven process that evaluates building operations, identifies waste and recommends cost-effective remedies. Through field-testing both systems and components on campus, $\mathrm{RCx}$ identifies proven operational and maintenance improvements that cut energy and costs.

In a new initiative that builds on $\mathrm{RCx}$ principles, the Energy Services Department (ESD) has begun constantly monitoring and analyzing energy use at the Bluemle Life Sciences Building. The ESD has retained two firms to test this constant commissioning approach, known as CCx. With its' approach of constant surveillance, the results are promising.
Bruce Henderson, our Control Systems Supervisor, is the "rosin" that allows this "CCx team" to operate smoothly and efficiently. The equipment at BLSB under CCx scrutiny include chillers, cooling towers and over 1,000 terminal units. Our CCx team has been analyzing our systems round the clock, looking to improve our energy efficiency.

So far, we have saved $\$ 87,600$ and further results will be disclosed in the autumn 2014 edition of Currents.

Just because a system is operating smoothly is no guarantee that it's running efficiently. 


\section{Jefferson.}

Energy Services Department

214 South 11th Street, Room 400

Philadelphia, PA 19107

\section{Currents}

Brighit loleas

\section{A Triple Play}

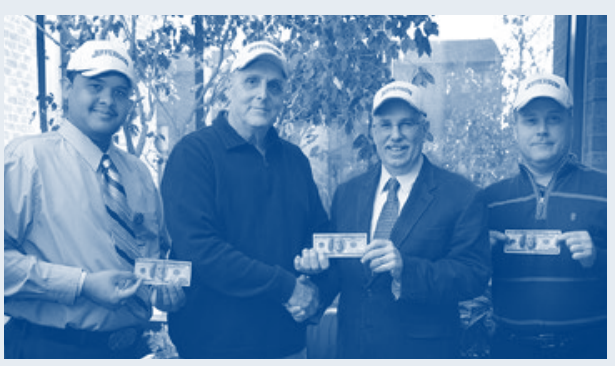

Caption: L.Williams, R. DiFalco, R. Haines, J. Andrews

By their very nature, hospitals rely on ambulances to ferry patients to and fro throughout the day and night in all manner of weather. To mitigate the discomfort of patients being moved during the heating season, the transfer station at Gibbon, aka "dock", is equipped with electric infrared heaters mounted in the ceiling of this exterior dock.

These infrared heaters are manally activated with a thermostat.
This arrangement has not been a very good energy operation until recently. Ronald DiFalco, a senior Biomedical Specialist III in Biomedical Instrumentation, had noticed employees overriding the thermostat, rendering the heating always ON, 24/7, even when there is no ambulance or employee present.

He suggested replacing the switch with an occupancy sensor to resolve this issue. Cost to implement $-\$ 300$. Savings $\$ 3,000 /$ year.

John Andrews, a mechanic from the Facilities Department, noticed that all 24 of the radiators installed to heat the north stair tower of the Edison Building were being used for this purpose, regardless of outside air temperatures. Indoor space temperatures were excessive and uncomfortable.
John, working with John McMillan, Supervisor, brought these indoor temperatures down to comfortable levels on the coldest days by securing $75 \%$ of these radiators. Cost to implement - None. Savings - \$6,600/year.

Lancess Williams, a campus security officer, noticed that all 54 light fixtures in the locker rooms and roll call area remained $\mathrm{ON}$, although these areas are vacant most of the time. Cost to install occupancy sensors $-\$ 900$. Savings $\$ 1,351 /$ year.

Note the common thread tying the three individuals cited above. They stretched their minds to look past the mundane routine and instead saw waste and reported it to the Energy Team's manager, Randy Haines at 3-6099. Couldn't you use a $\$ 100$ bill?

\section{Celebrate Earth Day on Tuesday, April 22.}
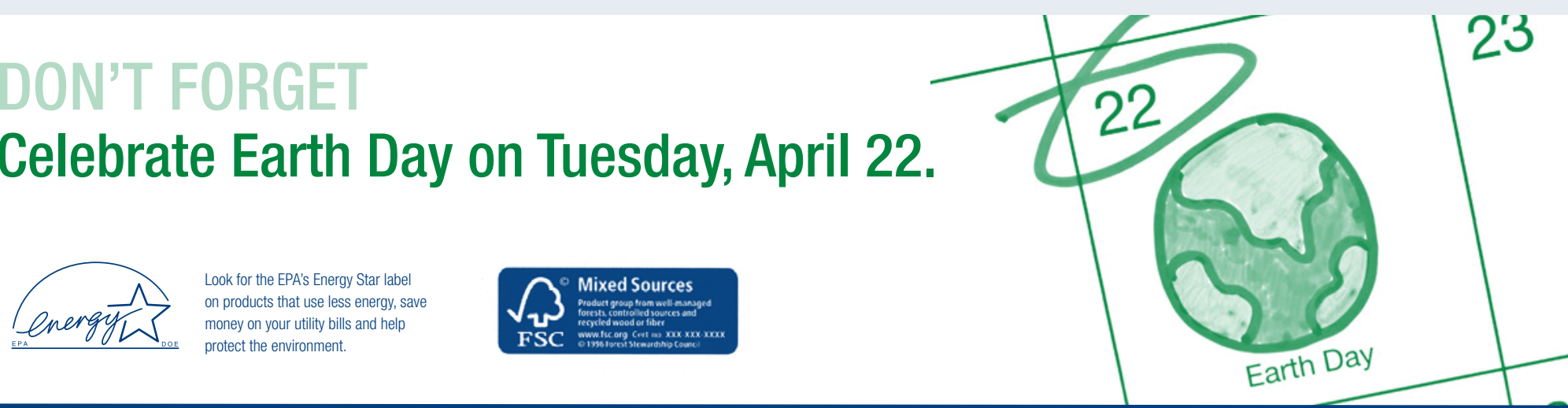